\title{
Out-of-bounds: The significance of extraprostatic extension on multiparametric magnetic resonance imaging for local staging of prostate cancer
}

\author{
Melissa Huynh, MD, MPH \\ Department of Surgery, Division of Urology, Schulich School of Medicine and Dentistry, Western University, London, ON, Canada
}

Cite as: Huynh M. Out-of-bounds: The significance of extraprostatic extension on multiparametric magnetic resonance imaging for local staging of prostate cancer. Can Urol Assoc J 2021;15(8):267-8. http://dx.doi.org/10.5489/cuaj.7496

See related article on page 261

$\mathrm{T}$ he use of multiparametric magnetic resonance imaging MRI (mpMRI) in the diagnosis of prostate cancer (PCa) has become increasingly widespread, with multiple studies demonstrating that MRI-targeted prostate biopsies, in conjunction with systematic biopsies, detect more clinically significant PCa than either method alone. ${ }^{1-3}$ This strategy also detects fewer indolent cancers and allows some men to avoid a biopsy all together. Moreover, mpMRI offers excellent soft tissue differentiation and is often also used for preoperative local staging.

In the single-institution retrospective study by Griffiths et al in this issue of CUA,${ }^{4}$ the authors examined the likelihood of pathological T3 disease in the radical prostatectomy (RP) specimen in 191 patients based on the finding of extracapsular extension on preoperative mpMRI (mECE) vs. the finding of perineural invasion ( $\mathrm{PNI}$ ) on prostate biopsy (PBx). $\mathrm{PNI}$ is routinely examined on $\mathrm{PBx}$, but its significance remains controversial and unclear. Some retrospective studies have found $\mathrm{PNI}$ to be independently associated with ECE at the time of RP, ${ }^{5}$ higher surgical Gleason score, ${ }^{6}$ positive margins, ${ }^{7}$ and biochemical recurrence. ${ }^{5}$ However, other studies have been unable to consistently demonstrate these findings, ${ }^{6,8}$ and some have argued that men with evidence of PNI in the biopsy specimen, who would otherwise be candidates for active surveillance, should not be excluded from this treatment option. ${ }^{9}$

In the study by Griffiths et al, PNI was present in $22.8 \%$ of biopsy specimens, and $37 \%$ of patients were found to have pT3+ PCa after undergoing RP. On mpMRI, mECE was classified as either present $(6.3 \%)$, suspicious $(16.8 \%)$, or absent $(77 \%)$. While the specificity was very high for definite ECE
(98.3\%), the sensitivity of reporting definite ECE or suspicious ECE on MRI was only $14.1 \%$ (95\% confidence interval [Cl] 7.3-24.8), and 23.9\% (95\% Cl 4.9-35.8), respectively. When the authors examined the subset of patients without suspicion for mECE, PNI was not associated with increased risk of pT3+ disease. The authors concluded that the definite presence of ECE on MRI was 4.84 times more likely to result in worse pathological stage on RP compared to 2.25 times more likely when $\mathrm{PNI}$ is present at the time of PBx. Interestingly, suspicious ECE did not have the same predictive value for $\mathrm{pT} 3+$ disease, suggesting that further improvements in the ability to detect ECE are still necessary.

A meta-analysis of 45 studies examining the accuracy of MRI reported that the sensitivity for ECE is only $57 \%$ (95\% Cl 49-64), while the specificity was $91 \%(95 \% \mathrm{Cl}$ 88-93). ${ }^{10}$ The sensitivity for the detection of EPE, therefore, remains low across many studies in the literature, despite the advances in prostate imaging. The authors acknowledge that the reporting of ECE is not standardized, unlike the Prostate Imaging Reporting \& Data System (PI-RADS) scoring system, and interobserver variability may affect interpretation. One of the challenges of detecting ECE on imaging is the fact that many patients may have ECE that is microscopic or very focal in nature, and these patients would be expected to have a more favorable prognosis than those with the extensive ECE that would otherwise be grossly visible on imaging. ${ }^{11-13}$ Nevertheless, with the increasing use of $\mathrm{mpMRI}$ in the diagnosis and staging of $\mathrm{PCa}$, the findings of this study are thought-provoking and certainly worthy of further investigation.

Competing interests: The author does not report any competing personal or financial interests related to this work. 
Huynh

\section{References}

1. Kasivisvanathan V, et al. MRL-targeted or standard biopsy for prostate cancer diagnosis. N Engl J Med 2018;378:1767-77. https://doi.org/10.1056/NEJMoa1801993

2. Rouvière 0 , et al. Use of prostate systematic and targeted biopsy on the basis of multiparametric MRI in biopsy-naive patients (MRI-FIRST): A prospective, multicenter, paired diagnostic study. Lancet Oncol 2019;20:100-9. https://doi.org/10.1016/S1470-2045(18)30569-2

3. Ahdoot $M$, et al. MRl-targeted, systematic, and combined biopsy for prostate cancer diagnosis. N Engl J Med 2020;382:917-28. https://doi.org/10.1056/NEJMoa1910038

4. Griffiths $\mathrm{L}$, et al. Extracapsular extension on multiparametric magnetic resonance imaging better predicts pT3 disease at radical prostatectomy compared to perineural invasion on biopsy. Can Urol Assoc J 2021;15:261-6. https://doi.org/10.5489/cuaj.6909

5. Kang $M$, et al. Perineural invasion and lymphovascular invasion are associated with increased risk of biochemical recurrence in patients undergoing radical prostatectomy. Ann Surg Oncol 2016;23:26992706. https://doi.org/10.1245/s10434-016-5153-z

6. Kraus RD, et al. The perineural invasion paradox: Is perineural invasion an independent prognostic indicator of biochemical recurrence risk in patients with pT2NORO prostate cancer? A multi-institutional study. Adv Rad Oncol 2019:4:96-102. https://doi.org/10.1016/i.adro.2018.09.006

7. Reeves $\mathrm{F}$, et al. Does perineural invasion in a radical prostatectomy specimen predict biochemical recurrence in men with prostate cancer? Can Urol Assoc J 2015;9:252. https://doi.org/10.5489/cuaj.2619
8. Bismar TA, Lewis JS, Vollmer RT, et al. Multiple measures of carcinoma extent vs. perineural invasion in prostate needle biopsy tissue in prediction of pathologic stage in a screening population. Am I Surg Pathol 2003;27:432-40. https://doi.org/10.1097/00000478-200304000-00002

9. Al-Hussain T, Carter HB, Epstein JI. Significance of prostate adenocarcinoma perineural invasion on biopsy in patients who are otherwise candidates for active surveillance. I Urol 2011;186:470-3. https://doi.org/10.1016/i.juro.2011.03.119

10. de Rooij M, Hamoen EHJ, Wities JA, et al. Accuracy of magnetic resonance imaging for local staging of prostate cancer: A diagnostic meta-analysis. Eur Urol 2016;70:233-45. https://doi.org/10.1016/i. eururo.2015.07.029

11. Chuang A-Y, Nielsen ME, Hernandez DJ, et al. The significance of positive surgical margin in areas of capsular incision in otherwise organ-confined disease at radical prostatectomy. J Urol 2007;178:1306-10. https://doi.org/10.1016/i.juro.2007.05.159

12. Padhani AR, Petralia $G$, Sanguedolce F. Finding minimal extraprostatic disease: Who cares? Eur Urol 2016;70:246-7. hitps://doi.org/10.1016/i.eururo.2015.07.045

13. Ball MW, Partin AW, Epstein Jl. Extent of extraprostatic extension independently influences biochemical recurrence-free survival: Evidence for further pT3 subclassification. Urology 2015;85:161-4. https://doi.org/10.1016/i.urology.2014.08.025

Correspondence: Dr. Melissa Huynh, Department of Surgery, Division of Urology, Schulich School of Medicine and Dentistry, Western University, London, 0N, Canada; mihuynh9@gmail.com

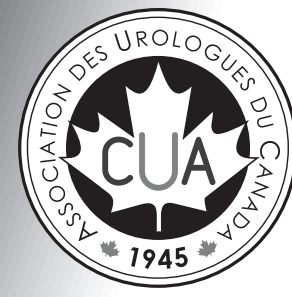

\section{Presidential Citation 2021}

Congratulations to the CUA's outgoing President,

Dr. Andrew MacNeily, who received the 2021

Presidential Citation at the recent virtual 2021

CUA annual meeting. The Presidential Citation is

an award recognizing a singularly outstanding

contribution by an individual in support of the

CUA's mission. Dr. MacNeily was recognized for

his exemplary leadership during these last two

challenging and unprecedented years.

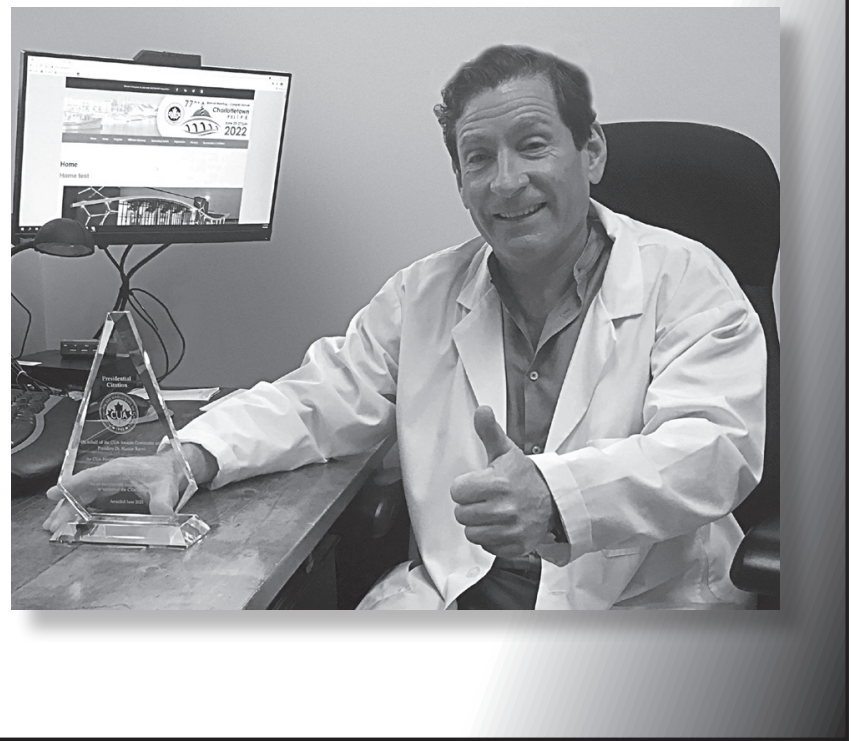

